\title{
Changes in clinical and laboratory findings at the time of diagnosis of primary hyperparathyroidism in a University Hospital in São Paulo from 1985 to 2002
}

M.N. Ohe ${ }^{1}$, R.O. Santos ${ }^{2}$, E.R. Barros ${ }^{1}$, A. Lage ${ }^{1}$, I.S. Kunii ${ }^{1}$, M. Abrahão ${ }^{2}$, O. Cervantes ${ }^{2}$, O.M. Hauache ${ }^{1}$, M. Lazaretti-Castro ${ }^{1}$ and J.G.H. Vieira ${ }^{1}$
${ }^{1}$ Disciplina de Endocrinologia e Metabologia, Departamento de Medicina, ${ }^{2}$ Disciplina de Cirurgia de Cabeça e Pescoço, Departamento de Otorrinolaringologia e Cirurgia de Cabeça e Pescoço, Escola Paulista de Medicina, Universidade Federal de São Paulo, São Paulo, SP, Brasil

\section{Correspondence}

M.N. Ohe

Av. Cons. Rodrigues Alves, 804

Apto. 51

04014-002 São Paulo, SP

Brasil

E-mail: moniqueohe@uol.com.br

Publication supported by FAPESP.

....................

Received September 9, 2004 Accepted April 29, 2005

\begin{abstract}
In contrast to most developed countries, most patients with primary hyperparathyroidism in Brazil are still symptomatic at diagnosis. However, we have been observing a change in this pattern, especially in the last few years. We evaluated 104 patients, 77 females and 27 males aged 11-79 years (mean: 54.4 years), diagnosed between 1985 and 2002 at a University Hospital. Diagnosis was made on the basis of clinical findings and of high total and/or ionized calcium levels, high or inappropriate levels of intact parathyroid hormone and of surgical findings in 80 patients. Patients were divided into three groups, i.e., patients diagnosed from 1985 to 1989 , patients diagnosed from 1990 to 1994 , and patients diagnosed from 1995 to 2002 . The number of new cases diagnosed/year increased from 1.8/year in the first group to $6.0 /$ year in the second group and 8.1/year in the third group. The first group comprised 9 patients (mean serum calcium \pm SD, $13.6 \pm 1.6 \mathrm{mg}$ / $\mathrm{dl}), 8$ of them $(88.8 \%)$ defined as symptomatic. The second group comprised 30 patients (mean calcium $\pm \mathrm{SD}, 12.2 \pm 1.63 \mathrm{mg} / \mathrm{dl}$ ), 22 of them defined as symptomatic (73.3\%). The third group contained 65 patients (mean calcium $11.7 \pm 1.1 \mathrm{mg} / \mathrm{dl}$ ), 34 of them symptomatic $(52.3 \%)$. Patients from the first group tended to be younger (mean \pm $\mathrm{SD}, 43.0 \pm 15$ vs $55.1 \pm 14.4$ and $55.7 \pm 17.3$ years, respectively) and their mean serum calcium was significantly higher $(\mathrm{P}<0.05)$. All of symptomatic patients independent of group had higher serum calcium levels $(12.4 \pm 1.53 \mathrm{mg} / \mathrm{dl}, \mathrm{N}=64)$ than asymptomatic patients (11.4 \pm $1.0 \mathrm{mg} / \mathrm{dl}, \mathrm{N}=40$ ). Our data showed an increase in the percentage of asymptomatic patients over the years in the number of primary hyperparathyroidism cases diagnosed. This finding may be due to an increased availability of diagnostic methods and/or to an increased awareness about the disease.
\end{abstract}

Key words

- Primary hyperparathyroidism

- Hypercalcemia

- Clinical presentation

- Asymptomatic primary

hyperparathyroidism

- Parathyroid hormone

- Hyperparathyroidism 
Primary hyperparathyroidism (PHP) is a hypercalcemic disease due to an abnormally increased secretion of parathyroid hormone (PTH) from one or more parathyroid glands. The hallmark of this condition is the presence of high levels of serum calcium and high or inappropriate levels of PTH. PHP is a common disease and in 1999, about 22,000 individuals had a discharge diagnosis of PHP in the United States, and PHP was the firstlisted diagnosis in 5000 of them (1). The incidence of hospitalization for PHP was 8.0 per 100,000 per year, counting "all listed" diagnoses, and 1.8 per 100,000 counting only the first-listed diagnoses (2). In Europe, the introduction of serum calcium screening in the early 1970's made possible the identification of a large number of "asymptomatic" patients (3). This led also to a 5-fold increase in the apparent incidence of PHP for the identification of patients who where never diagnosed before (3). As soon as this cohort of usually asymptomatic patients was identified (catch up-effect) a decline in the rate of diagnosis of new cases was anticipated from the 1970's to the 1990's (3). In the most recent and accurate study, a 21/ 1000 prevalence of PHP was found in women aged 55-75 years, which is equivalent to a $3 /$ 1000 prevalence in the general population (3). The incidence of PHP rises with age, from nonreportable at ages less than 45 years to 11.9 per 100,000 at the ages of $45-64$ years and to 40.9 per 100,000 among those aged 65 years and over in the United States (1). PHP is more common in women, with a $70 \%$ higher overall hospitalization rate among women than men (12.2 vs 7.2 per 100,000 per year) in the United States in 1999 (2). PHP is caused by a solitary adenoma in almost $80 \%$ of cases; hyperplasia of all four glands is seen in 15 to $20 \%$ and carcinoma is a very rare cause of PHP, accounting for less than $0.5 \%$ of the cases (4). When PHP was first described in the 1930's, it was considered to be a rare disease and its clinical presentation was that of a disabling condition, with predominance of bone symptoms. Nowadays, in the United States, most patients with PHP have few or no symptoms at diagnosis (5) and calcium levels are not usually higher than $1 \mathrm{mg} / \mathrm{dl}$ above the upper normal limits (6). However, in a previous publication we showed a higher incidence of symptomatic patients by the time of diagnosis among Brazilian patients (7). These differences in clinical presentation of PHP might be related to several causes, including awareness about the disease, availability of laboratory resources and vitamin D status.

The purpose of the present study was to evaluate changes in clinical and laboratory presentation of PHP at our University Hospital. The study was retrospective. Reports of 104 patients with PHP diagnosed between 1985 and 2002 were reviewed. There were $77(74 \%)$ females and $27(25.9 \%)$ males (2.8:1 ratio). Age ranged from 11 to 79 years, with a mean age at diagnosis of 54.4 years. PHP was diagnosed on the basis of the finding of high levels of total and/or ionized calcium and high or inappropriate PTH levels. In our Endocrinology unit, calcium measurements are performed in a systematic way and are responsible for the diagnosis of asymptomatic PHP. However, some patients were referred to our unit after they had shown hypercalcemia in a laboratory investigation of osteoporosis and/or kidney stones. In 80 patients the diagnosis was confirmed by surgery. Patients did not undergo surgery if they presented co-morbidities and a high surgical risk or if they refused surgical treatment. Based on their clinical presentation, patients were classified as symptomatic or asymptomatic. We defined as symptomatic patients who presented typical bone disease (we did not consider osteopenia as a typical bone disease), hypercalcemic metabolic syndrome, and/or recurrent stone disease. $\mathrm{Pa}$ tients were divided into three groups according to the year of diagnosis: the first included patients diagnosed from 1985 to 1989 , the second patients diagnosed from 1990 to 
1994, and the third patients diagnosed from 1995 to 2002. These groups were defined according to available laboratory methods for PHP diagnosis: ionized calcium measurements were available after 1990 and intact PTH measurements were available after 1994. Up to 1993 PTH was measured using an amino-terminal specific radioimmunoassay (8); from 1994 on, intact PTH was measured using an immunofluorometric assay (reference values: 10-70 pg/ml) (9); ionized calcium (available only from 1990 on) was measured with an ion-specific electrode (AVL 9180 Electrolyte Analyzer, Roswell, GA, USA; reference values: $1.12-1.32 \mathrm{mmol} /$ 1), and total calcium by colorimetric assays (reference values: 8.5-10.5 mg/dl). Mean PTH values considered only intact PTH. Data were analyzed by the unpaired $t$-test, unpaired $t$-test with Welsh correction and by ANOVA, as appropriate, with the level of significance set at $\mathrm{P}<0.05$.

In 71 patients we measured both total and ionized calcium, and a correlation (Spearman) of $\mathrm{r}=0.782(\mathrm{P}<0.05)$ was obtained. The first group of patients (1985-1989) comprised 9 patients (mean serum calcium of $13.6 \pm 1.6 \mathrm{mg} / \mathrm{dl}), 8$ of them $(88.8 \%)$ defined as symptomatic; all underwent surgery. The second group of patients (1990-1994) included 30 patients (mean serum calcium of $12.2 \pm 1.63 \mathrm{mg} / \mathrm{dl}), 22$ of them $(73.3 \%)$ classified as symptomatic; 27 of these patients were operated upon (90\%). The third group (1995-2002) comprised 65 patients (mean serum calcium of $11.7 \pm 1.1 \mathrm{mg} / \mathrm{dl}$ ), $34(52.3 \%)$ classified as symptomatic; 44 were operated upon (67.6\%). The number of new cases increased from 1.8/year in the first group to 6.0/year in the second group and $8.1 /$ year in the third group. Among the 80 patients operated upon, surgical findings showed adenomas in $75 \%$, double adenoma in $1.2 \%$, hyperplasia in $11.2 \%$, and carcinomas in $7.5 \%$. Patients from the first group tended to be younger $(43.0 \pm 15.07$ years $)$ than patients of the second group (55.1 \pm
14.47 years, $P=0.0357$ ) and the third group $(55.7 \pm 17.13$ years, $P=0.0382)$, and their mean total calcium levels were significantly higher $(\mathrm{P}<0.05)$. All symptomatic patients had higher total calcium levels $(12.43 \pm 1.53$ $\mathrm{mg} / \mathrm{dl})$ than asymptomatic ones $(11.43 \pm 1.0$ $\mathrm{mg} / \mathrm{dl}, \mathrm{P}=0.0014)$; the total PTH levels were also higher in the symptomatic patients $(\mathrm{N}=35,463.8 \pm 572.6 \mathrm{pg} / \mathrm{ml})$ compared to the asymptomatic ones $(\mathrm{N}=38,213.8 \pm$ $276.3 \mathrm{pg} / \mathrm{ml} ; \mathrm{P}=0.0233$ ).

It is well known that the clinical features of PHP are related to the continuous action of PTH and correlate with the degree of hypercalcemia. The initial presentation of PHP has changed over the years in developed countries, with a marked increase in number of patients with few or no symptoms. The reasons for this tendency may be related to more widespread use of screening tests, especially serum calcium measurements. Data from developing countries indicate a lower number of new cases who mainly consist of patients with a dramatic clinical and laboratory presentation by the time of diagnosis $(7,10,11)$. The data showed a changing pattern. The number of new cases of asymptomatic patients increased over the years (Figure 1), and calcium levels at the time of diagnosis were lower. In addition, among asymptomatic subjects, calcium and PTH levels were lower than among symptomatic ones. All of these findings reflect an

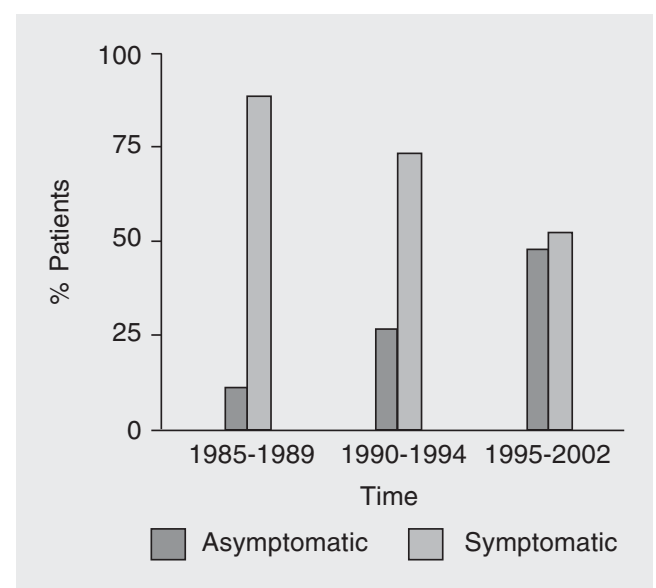

Figure 1. Percentage of symptomatic and asymptomatic hyperparathyroidism patients diagnosed from 1985 to 2002 at our University Hospital. Data are reported for 64 symptomatic and 40 asymptomatic patients. 
earlier diagnosis. Some reasons for this might be related to an increased availability of diagnostic methods such as those for ionized calcium and intact PTH measurements. It is interesting to note that, after observing all of these changes, we have been paying more attention to the disease and we have been searching for these asymptomatic PHP patients. Furthermore, it is important to point out that, as part of the staff of a Medical School, we have been discussing these findings with other departments, contributing to an increasing awareness about the disease.

We have observed a higher incidence of PHP patients with carcinomas (7.5\%) than reported in literature (12). The reasons for this apparent higher incidence may be as follows: first, we believe we do not have more PHP patients with carcinomas than other countries in absolute numbers; in fact, we are still misdiagnosing asymptomatic patients. Therefore, the proportions of carcinoma are apparently higher than expected. A second reason for this higher incidence is related to the clinical profile of PHP observed in the past. We had many symptomatic patients with dramatic bone disease, and the probability of finding patients with carcinomas in a group with these characteristics is higher.

The changing spectrum of PHP over the world has led to a controversial idea, i.e., the existence of normocalcemic PHP. The patients with this condition would have no symptoms and would show high PTH levels with normal serum calcium, and would be considered to be in the early stages of the disease (13). However, some questions remain regarding the vitamin $\mathrm{D}$ status of these patients. Low levels of vitamin D are common in elderly people (14) and it is still difficult to determine appropriate values of vitamin D in order to suppress PTH levels in these subjects. Considering the high incidence of PHP in patients aged 60 years or older, it might be difficult to define in some cases presenting high levels of PTH with normal serum calcium whether this is due to autonomous parathyroid stimuli or to a response to low levels of vitamin D. The association of higher PTH levels in PHP patients with vitamin D deficiency $(10,15-17)$ raises the possibility that the regional differences in clinical presentation may also be dependent on a higher prevalence of vitamin $D$ deficiency. Also, the inverse correlation between vitamin D status and parathyroid adenoma weight may be the explanation for the more severe cases described in vitamin D-deficient areas (18).

Our data show an increase in the number of cases diagnosed in the last years involving not only symptomatic patients, but also asymptomatic ones. These findings may be due to several reasons, the most probable ones being the increased awareness about PHP and the more widespread availability of diagnostic tests to detect the presence of PHP.

\section{References}

1. Popovic JR (2001). 1999 National Hospital Discharge Survey: Annual Summary with Detailed Diagnosis and Procedure Data. DHHS Publication No. (PHS) 2001-1722. U.S. Department of Health and Human Services, Hyattsville, MD, USA.

2. Melton III LJ (2002). The epidemiology of primary hyperparathyroidism in North America. Journal of Bone and Mineral Research, 17 (Suppl 2): N12-N17.

3. Adami S, Marcocci C \& Gatti D (2002). Epidemiology of primary hyperparathyroidism in Europe. Journal of Bone and Mineral Research, 17 (Suppl 2): N18-N23.

4. Wynne AG, Van Heerden J, Carney JA et al. (1992). Parathyroid carcinoma: clinical and pathologic features in 43 patients. Medicine, 71: 197-205.

5. Silverberg SJ, Shane E, Thomas PJ et al. (1999). A 10-year prospective study of primary hyperparathyroidism with or without parathyroid surgery. New England Journal of Medicine, 341: 1249-1255.

6. Bilezikian JP (1999). Primary hyperparathyroidism. In: Favus MJ (Editor), Primer on the Metabolic Bone Diseases Disorder of Mineral Metabolism. 4th edn. Chicago, IL, USA, 187-192.

7. Hauache OM, Amarante ECJ, Mendoza B et al. (1995). Análise clínica, laboratorial e achados cirúrgicos de 28 casos de hiperparatiroidismo primário. Arquivos Brasileiros de Endocrinologia e Meta- 
bologia, 39: 157-162.

8. Vieira JGH, Oliveira MAD, Maciel RMB et al. (1986). Development of a homologous radioimmunoassay for the synthetic amino terminal (1-34) fragment of human parathyroid hormone using egg yolkobtained antibodies. Journal of Immunoassay, 7: 57-72.

9. Vieira JGH, Nishida SK, Kasamatsu TS et al. (1994). Development of an immunofluorometric assay for intact parathyroid hormone. Brazilian Journal of Medical and Biological Research, 27: 23792382.

10. Bilezikian JP, Meng X, Shi Y et al. (2000). Primary hyperparathyroidism in women: a tale of two cities: New York and Beijing. International Journal of Fertility and Women's Medicine, 45: 158-165.

11. Biyabani SR \& Talati $J$ (1999). Bone and renal stone disease in patients operated for primary hyperparathyroidism in Pakistan: is the pattern of disease different from the west? Journal of the Pakistan Medical Association, 49: 194-198.

12. Morimitsu LK, Uyeno MNO, Goulart ML et al. (2001). Carcinoma de paratiróide: características clínicas e anátomo-patológicas de cinco casos. Arquivos Brasileiros de Endocrinologia e Metabologia, 45: 148-156.

13. Silverberg SJ \& Bilezikian JP (2003). "Incipient” primary hyperpara- thyroidism: a "forme fruste" of an old disease. Journal of Clinical Endocrinology and Metabolism, 88: 5348-5352.

14. Souberbielle JC, Cormier C, Kindermans C et al. (2001). Vitamin D status and redefining serum parathyroid hormone reference range in the elderly. Journal of Clinical Endocrinology and Metabolism, 86: 3086-3090.

15. Silverberg SJ, Shane E, Dempster DW et al. (1999). The effects of vitamin $D$ insufficiency in patients with primary hyperparathyroidism. American Journal of Medicine, 107: 561-567.

16. Kantorovich V, Gacad MA, Seeger LL et al. (2000). Bone mineral density increases with vitamin $D$ repletion in patients with coexistent vitamin D insufficiency and primary hyperparathyroidism. Journal of Clinical Endocrinology and Metabolism, 85: 3541-3543.

17. Harinarayan DV, Gupta N \& Kochupillai N (1995). Vitamin D status in primary hyperparathyroidism in India. Clinical Endocrinology, 43: 351-358.

18. Rao DS, Honasoge M, Divine GW et al. (2000). Effect of vitamin D nutrition on parathyroid adenoma weight: pathogenetic and clinical implications. Journal of Clinical Endocrinology and Metabolism, 85: 1054-1058. 